\title{
Mechanism Research of Emotional Intelligence
}

\author{
Xuanfang Hou, Xiaoyun Shao \\ College of Business, Jiangxi Normal University, Jiangxi, Nanchang 330022,China
}

Keywords: Emotional Intelligence, Mechanism

\begin{abstract}
Emotional intelligence could affect job performance. As a kind of ability, emotional intelligence has been widely used in enterprise development. But, so far, there are different points of view among scholars about how the emotional intelligenceaffects job performance. In this paper, from the two aspects,namely, direct effect and indirect effect of emotional intelligence on job performance, the authoradjusted the mechanism research of emotional intelligence. Besides, the author puts forward corresponding suggestions for future researches.
\end{abstract}

\section{Introduction}

Since Goleman(1995) had brought interpersonal relationship, self perception and other personality characteristics into emotional intelligence, companies began to realize the importance of emotional intelligence, and they tried to improve job performance by emotional intelligence. Knowledge and technology is no longer the only index to improve performance. Besides, a high level of emotional intelligence is an essential part of employees in the enterprise in pursuit of excellence. People with high emotional intelligence can better understand other people's ideas, and they know how to keep good relationship with employees in the management process. Therefore, they could make the employees move toward the direction that would be beneficial tothe organizations(Xavier, 2005), ensuring that the people, in the face of the pressure, organizational change, better adjust their mentalityto get a good mark in the workplace(Salleh \& Rahman, 2014). Thus,emotional intelligence can be providedas an index for enterprises to select leaders. What kind of role the emotional intelligence plays while the workers are in work state exactly? Based on the existed researches, we clear up role of emotional intelligence from the two aspects, namely, the direct and indirect aspects.

Direct Influences. Existing researches show that the emotional intelligence bears direct influence on job performance, job satisfaction, job involvement, job behavior and so on.

Bailey \& Sass(2004) proved that, in predictingstudents' collaborative team performance, the emotional intelligence bore higher accuracy than big five personalities, cognitive intelligence and other aspects in the prediction of leadership abilities.Emotional awareness and emotional understanding ability emotional intelligence were highly associated withjob performance,and the overall level of emotional intelligence was related to moderatejob performance. Feng Fenshan(2009), has taken the insurance marketing personnel as the research objects, and she found that the employee's emotional intelligence could positively influence on job performance and task performance. Besides, she found that, the emotional self motivationdimension bore significant positive influence on its contextual performance. Therefore, she held that the staff that could reasonablycontrol their emotions was better at identifying and mediating the emotions of others in work, and therefore being handier at work.

Zhang Huihua(2011) had conducted meta-analysis of 87 independent samples of75 researched. He got similar conclusions, and he held that the influence of emotional was greater than task 
performance, which showed that task performance was more dependent on intelligence and professional skills, while the background performance was more dependent onemotional intelligence. Newman's (2010) meta-analysis showed that in service industry (retail, insurance, etc.) that in need of emotional labor, emotional intelligence bore good predictability on job performance. The following year, Oboyle \& Humphrey (2011), based on the three kinds of models (capacity, self-reported, mixed),conducted researches respectively. And all the resultsproved that the emotional intelligence could positively predict job performance.

Tram \& Hara (2006), based onthe data analysisin a survey of a restaurant, found that there was a direct link between the emotional intelligence degree of the leadership andthe degree of employee satisfaction. Ealias \& George (2012) conducted an empirical research of 208 respondents of an India's operating international electronic company. This research showed that there is a high positive correlation between emotional intelligence andjob satisfaction. Based on this, Ealias \& George (2012) held that, positive action, in addition to rational thinking, for inspiring and guiding behavior, emotion played a certain guiding role. Employees With different levels of emotional intelligence would adapt different strategies while dealing with emotional problems, and the employeeswith higher levels of emotional intelligence rarely showed impulsive behaviorsthat would jeopardize organization's productivity (Mikolajczak; 2007).

Indirect Influences. Self-efficacy that based on social cognitive theory was usually referredas intermediate variable between emotional intelligence and work performance (Zhang Huihua, LingWenquan, 2006; Yang Hui-fang, Gu Jianping, 2007). Zhang Huihua, LingWenquan(2008) use the emotional intelligence scale of managers developed by themselves, and this scale was developed based on the Chinese cultural background. They used the methods of self-assessment and others' evaluation, in three times to collect research data, to study the relationship between emotional intelligence and performance results. Finally, they confirmed that the self-efficacy and leadership, in managers' emotional intelligence and job performance, played an intermediary role. Yang Hui-fang, Gu Jianping (2007), withgroup testing method, have conducted researches of the way of emotional intelligence and self-efficacy of 211 enterprise managers. They concluded that emotional intelligence and self-efficacy bore different predictive powerstowards the management performance of different levels, different jobs in different areas.

In addition, the leader-subordinate exchange of social exchange theory caused the attention of the academia for its mediation roleemotional intelligence influences. Yu Qiong, Yuan Denghua (2008) proved the influence of leader-subordinate exchange from the following two aspects, namely, task performance and scene performance. They confirmed that the emotions could through influencing social interactions further lead to exchange relationship between leader and employees in various degrees. The relationship with high quality could make the subordinates work hard, and they would give high performance in return. In turn, the relationship with low quality, would leadto poor performance.

Finally, the work pressure, fair atmosphere, job satisfaction, etc were often used to explain the mechanism of emotional intelligence. Liu Xiaoyu (2008) has analyzed intermediary role of workpressure in the relationship between emotional intelligence and job burnout. The resultsindicated that in the process of emotional intelligence affecting emotional exhaustion, job stress was a full mediation variable; but in the relationship between the other two dimensions of emotional intelligence and job burnout (cynicism andlow accomplishment), the work stress had partial intermediary effect. Zhu Renqi (2013) confirmed this conclusion and put forward that the organization could through developing employees' emotional intelligence, to the greatest degree reduce or even eliminate the negative pressure effect, thus to improve the employee's work 
efficiency as a whole. Emotional intelligence and job satisfaction were highly related to each other, and job satisfaction can be part of the mediation emotional intelligence and work deviation behavior (George, 2012). Fair atmosphere played a mediating role of the emotional intelligence between team performanceand attitude. Besides, the team power distance could adjust the relationship between emotional intelligence and fair atmosphere (RongYan, 2015). Because the mechanism of action of emotional intelligence was not unified, there we make a simple summary of the common mediation variables affecting the role of emotional intelligence in the following table.

Table 2-3-4 Indirect Impact of Emotional Intelligence on Related Researches

\begin{tabular}{|c|c|c|}
\hline $\begin{array}{l}\text { Intervening } \\
\text { variable }\end{array}$ & Researchers & Concrete results \\
\hline \multirow[t]{2}{*}{ Self-efficacy } & $\begin{array}{l}\text { Zhang Huihua, } \\
\text { Ling Wenshuan } \\
\text { (2008) }\end{array}$ & $\begin{array}{l}\text { Emotional intelligence of managers, through the management } \\
\text { of partial mediation effect of self-efficacy on its performance, } \\
\text { self-efficacy could adjustthe relationship between the emotional } \\
\text { intelligence of managers and the leadership }\end{array}$ \\
\hline & $\begin{array}{l}\text { Yang } \\
\text { Huifang,Gu } \\
\text { Jianping(2007) }\end{array}$ & $\begin{array}{l}\text { Emotional intelligence, self-efficacy bears differentpredictive } \\
\text { powers on the managers' performance of levels, different } \\
\text { positions and different areas }\end{array}$ \\
\hline $\begin{array}{l}\text { Leaders-subord } \\
\text { inates exchange }\end{array}$ & $\begin{array}{l}\text { Yu Qiong,Yuan } \\
\text { Denghua(2008) }\end{array}$ & $\begin{array}{l}\text { From the two aspects, namely, situation and task performance, } \\
\text { they respectivelyverified the intermediary role of the } \\
\text { leaders-subordinates exchange in the influence of } \\
\text { managers'emotional intelligence on the employees }\end{array}$ \\
\hline \multirow[t]{2}{*}{ Work pressure } & $\begin{array}{l}\text { Liu Xiaoyu } \\
\text { (2008) }\end{array}$ & $\begin{array}{l}\text { Work stress plays completely an intermediary role in the } \\
\text { influence of emotional intelligence on jobburnout. In specific,it } \\
\text { plays a partial intermediary role in the following two } \\
\text { dimensions: cynicism andlow accomplishment }\end{array}$ \\
\hline & $\begin{array}{c}\text { Zhu } \\
\text { Renqi(2013) }\end{array}$ & $\begin{array}{l}\text { Emotional intelligence in the process of influencing task } \\
\text { performance, the work stress could completely play a mediating } \\
\text { role; in the process of affecting associated performance and } \\
\text { overall job performance, the emotional intelligence plays } \\
\text { partially a intermediary role }\end{array}$ \\
\hline $\begin{array}{l}\text { Equal } \\
\text { Atmosphere }\end{array}$ & $\begin{array}{c}\text { Rong } \\
\text { Yan(2015) }\end{array}$ & $\begin{array}{l}\text { A fair atmosphere, in the influence of emotional intelligence of } \\
\text { leadership on different levels of group work performance and } \\
\text { team commitments, it plays an intermediary role, and its role } \\
\text { lies in regulatingpower distance }\end{array}$ \\
\hline
\end{tabular}

\section{Summary}

Through summarizing, we find that most studies have concluded that emotional intelligence is related with work performance, and emotional intelligence could affect performance directly, and it also could indirectly affect the job performance. For the influence of emotional intelligence on the mechanism of action of job performance, people hold controversialopinions, working pressure (Liu Xiaoyu, 2008; Zhu Renqi, 2013), self-efficacy (Zhang Huihua, 2007; LingWen Quan, 2014), the relationship-related social capital (Zhang Huihua, 2011) and other factors, Maya, etc. (2014) have surveyed 120 grass-roots staff of three subsidiary companies, and they found that emotional 
intelligence could not predict job performance very good. So, there are still disputesabout the emotional intelligence's influence on the work. In the future, we should focus on the mechanism behind, and to find whether there is a potential mediation or moderator variables.

\section{Acknowledgment}

Fund Support:This study was supported by grants from the National Natural Science Foundation of China(71562021), the Social science planning project of Jiangxi Province (15GL14), and the Research project of Humanities and Social Sciences in Universities of Jiangxi Province (GL1559).

\section{References}

[1] Ealias A, George J. Emotional Intelligence and Job Satisfaction: A Correlational Study[J]., 2012.

[2] Goleman, D. Emotional intelligence. New York: Bantanm Books.1995:41-42

[3] Noor, Maya, Salleh, et al. Frontline Staff' s Emotional Intelligence and Creativity Impact on Job Performance[J]., 2014.

[4] Xavier K B, Bassler B L. Regulation of Uptake and Processing of the Quorum-Sensing Autoinducer AI-2 in Escherichia coli[J]. Journal of Bacteriology, 2005, 187(1): 238-247.

[5] Liu Xiaoyu ZhangKai.Study on the Intermediary Role of Emotional Intelligence in Work Pressure on Job Burnout Mechanism[J]. Journal of Southwest Normal University (Natural Science Edition), 2008 03:148-154.

[6] RongYan SuiYang, Yang Baiyin. The Influence of Leaders’ Emotional Intelligence on Team Performance and Employees' Attitude - the Influence of Fair Atmosphere and Power Distance[J]. Journal of Psychology, 2015, (09) : 1152-1161.

[7] Yu Qiong, Yuan Denghua. The Emotional Intelligence of Employees and Managers on the Employees’ Job Performance[J]. Journal of Psychology, 2008,01:74-83.

[8] Zhang Huihua, LingWenquan, Fang Liluo. General Study of “Emotional Work”[J]. Progress in Psychological Science, 2006,01:111-119.

[9] Zhang Huihua, Wang Hui. Meta-analysis of the Relationship between Individual Emotional Intelligence and Work Performance[J]. Journal of Psychology, 2011, (02) : 188-202.

[10] Zhu Renqi, Chen Xiaochun, Peng Liming. Study on the Intermediary Role of Emotional Intelligence in Work Pressure on Job Burnout Mechanism[J]. Journal of Statistics and Information BBS, 2013, 02:104-108 